\title{
Citation:
}

Tang, K.S., \& Williams, P.J. (in press). STEM literacy or literacies? Examining the empirical basis of these constructs, Review of Education, doi: 10.1002/rev3.3162

This is the peer reviewed version of the following article: Tang, K.-S. and Williams, P.J. (2019), STEM literacy or literacies? Examining the empirical basis of these constructs. Rev Educ, 7: 675-697, which has been published in final form at https://doi.org/10.1002/rev3.3162. This article may be used for non-commercial purposes in accordance with Wiley Terms and Conditions for Use of Self-Archived Versions.

\section{STEM Literacy or Literacies? Examining the Empirical Basis of these Constructs}

Kok-Sing Tang and John Williams

Curtin University

Author Note

Kok-Sing Tang, STEM Education Research Group, School of Education, Curtin University;

John Williams, STEM Education Research Group, School of Education, Curtin University.

Correspondence concerning this article should be addressed to Kok-Sing Tang, Curtin

University, GPO Box U1987, Perth, Western Australia 6845, Australia

Email: kok-sing.tang@curtin.edu.au

Telephone: +61 892662080

Fax: +61 892663131 
Tang, K.S., \& Williams, P.J. (in press). STEM literacy or literacies? Examining the empirical basis of these constructs, Review of Education, doi: 10.1002/rev3.3162

\begin{abstract}
The term "STEM literacy", while often used as a slogan for the goal of STEM education, is open to multiple interpretations and used without much research evidence to support its validity. The purpose of this paper is to review the research literature in science, technology/engineering and mathematics education to examine how literacy in each respective discipline has been defined, conceptualised and studied. The literacies across the disciplines are then compared to identify similarities and differences in order to determine on what basis these literacies can be conceptualised collectively, or not. Based on the similarities found in several language and thought processes of the disciplines, we conclude there is presently a research basis for postulating a unitary STEM literacy that reflects the shared general capabilities required in all the STEM disciplines. At the same time, there are also substantial differences that support the retention of the existing literacy constructs (i.e., S.T.E.M. literacies) to reflect the specific linguistic, cognitive and epistemic requirements found in each disciplinary area. This distinction from the singular STEM literacy is necessary to highlight the skills and practices that are unique to each particular discipline, and therefore not applicable in all the other disciplines. Given the haphazard rhetoric regarding STEM education, what STEM literacy comprises requires analysis and clear articulation that is framed by literacy research and scholarship in each STEM discipline.
\end{abstract}

Keywords: Engineering literacy, mathematical literacy, scientific literacy, STEM literacy, technological literacy 
Tang, K.S., \& Williams, P.J. (in press). STEM literacy or literacies? Examining the empirical basis of these constructs, Review of Education, doi: 10.1002/rev3.3162

\section{STEM Literacy or Literacies? Examining the Empirical Basis of these Constructs}

The term "STEM literacy" is often defined broadly as an educational goal of STEM

(Science, Technology, Engineering, Mathematics) education that aims to prepare future workers and citizens for a modern and technological driven society. This goal is generally associated with a set of capabilities that a "STEM literate" person should have or is able to do; such as identifying questions and problems related to STEM, understanding characteristic features of STEM disciplines, and willingness to engage in STEM-related issues as a concerned and reflective citizen (Zollman, 2012). While useful as a rhetoric for political and curriculum reform, it is not exactly clear what STEM literacy comprises, let alone the tasks needed by educators to teach in STEM education. Consequently, there are multiple interpretations and views of STEM literacy in the literature. One common view of STEM literacy is almost synonymous with scientific literacy, with engineering and technology often added to complete the STEM acronym (e.g., Shiverdecker \& Fries-Gaither, 2015). Another view sees STEM literacy as an all-inclusive term that includes scientific, technological, engineering and mathematics literacies (e.g., Zollman, 2012). Yet another view sees STEM literacy as a completely new entity outside the four traditional disciplines but somewhat associated with a set of relevant skills or literacy practices needed in the $21^{\text {st }}$ century (e.g., digital literacies, tinkering; see Tucker-Raymond, Gravel, Kohberger, \& Browne, 2017). In our view, such wide ranging interpretations present an obstacle for the field to have meaningful conversation revolving around STEM literacy.

In an attempt to bring greater clarity to the field, the purpose of this paper is to review the research literature in science, technology/engineering and mathematics education and examine how literacy in each respective area has been defined, conceptualised and studied. Specifically, we aim to unpack the definition of the various literacies, review the research that substantiates or supports these notions of literacy, and identify key capabilities unique to each of the literacies concerned. We then compare these capabilities to identify similarities and differences in order to 


\section{Citation:}

Tang, K.S., \& Williams, P.J. (in press). STEM literacy or literacies? Examining the empirical basis of these constructs, Review of Education, doi: 10.1002/rev3.3162

determine on what basis these literacies can be conceptualised collectively, or not. Through this process, we aim to address the question of whether it is more meaningful to use the term "STEM literacy" or "S.T.E.M. literacies" for various research and pedagogical purposes. With this purpose in mind, the questions that guide this literature review are:

1) What are the unique literacies associated with each of the S. T. E. M. disciplines? What are their respective disciplinary emphases or focus?

2) How are the literacies for each discipline similar and different to one another?

3) To what extent can the literacies for each S. T. E. M. discipline be grouped together, and for what purpose, under a common concept of literacy, i.e. STEM literacy?

It is important to point out that there have been many literature reviews focusing on STEM education (e.g., Yore, 2011). Some have provided a synthesis of various nationwide STEM programs and initiatives (e.g., DeCoito, 2016; Williams, 2011) and approaches to STEM integrated curriculum (e.g., Chalmers, Carter, Cooper, \& Nason, 2017; English, 2017). The focus of this literature review is however on literacy, which is generally regarded as the sum of the competencies needed for meaningful participation in the society (see definitions later).

\section{Definitions \& Scope of Review}

We begin the review by examining several key definitions by influential organisations to put forward their rationale for curricular changes and reform in STEM-related areas. As an example, Table 1 shows the definitions of scientific literacy, mathematical literacy, engineering and technological literacy from the Organisation for Economic Co-operation and Development (OECD; 2003, 2006) and the International Technology Education Association (ITEA, 2000). These definitions reveal 3 common dimensions of how literacy includes: (a) an understanding of the disciplinary knowledge and processes, (b) an ability to apply the disciplinary knowledge for personal use and (c) an awareness of one's civic responsibility and engagement with social issues. 
Citation:

Tang, K.S., \& Williams, P.J. (in press). STEM literacy or literacies? Examining the empirical basis of these constructs, Review of Education, doi: 10.1002/rev3.3162

Table 1

Key Definitions of Scientific, Mathematical, Engineering and Technological Literacy

\begin{tabular}{|c|c|c|}
\hline Literacy & Organisation & Definition \\
\hline $\begin{array}{l}\text { Scientific } \\
\text { literacy }\end{array}$ & $\begin{array}{l}\text { (OECD, } \\
2006)\end{array}$ & $\begin{array}{l}\text { An individual's scientific knowledge and use of that knowledge } \\
\text { to identify questions, to acquire new knowledge, to explain } \\
\text { scientific phenomena, and to draw evidence-based conclusions } \\
\text { about science-related issues, understanding of the characteristic } \\
\text { features of science as a form of human knowledge and enquiry, } \\
\text { awareness of how science and technology shape our material, } \\
\text { intellectual, and cultural environments, and willingness to engage } \\
\text { in science-related issues, and with the ideas of science, as a } \\
\text { reflective citizen. }\end{array}$ \\
\hline $\begin{array}{l}\text { Mathematical } \\
\text { literacy }\end{array}$ & $\begin{array}{l}\text { (OECD, } \\
2006)\end{array}$ & $\begin{array}{l}\text { An individual's capacity to identify and understand the role that } \\
\text { mathematics plays in the world, to make well-founded } \\
\text { judgments, and to use and engage with mathematics in ways that } \\
\text { meet the needs of that individual's life as a constructive, } \\
\text { concerned, and reflective citizen. }\end{array}$ \\
\hline $\begin{array}{l}\text { Technological } \\
\text { literacy }\end{array}$ & ITEA (2010) & $\begin{array}{l}\text { A technologically literate person understands, in increasingly } \\
\text { sophisticated ways that evolve over time, what technology is, how } \\
\text { it is created and how it shapes society and in turn is shaped by } \\
\text { society. He or she will be able to hear a story about technology on } \\
\text { television or read it in the newspaper and evaluate the information } \\
\text { in the story intelligently, put that information in context, and form } \\
\text { an opinion based on that information }\end{array}$ \\
\hline $\begin{array}{l}\text { Engineering } \\
\text { literacy }\end{array}$ & $\begin{array}{l}\text { (OECD, } \\
2003)\end{array}$ & $\begin{array}{l}\text { The understanding of how technologies are developed via the } \\
\text { engineering design process. This incorporates the ability to } \\
\text { systematically and creatively apply scientific and mathematical } \\
\text { principles to practical ends, such as the design, manufacture, and } \\
\text { operation of efficient and economical structures, machines, } \\
\text { processes, and systems }\end{array}$ \\
\hline
\end{tabular}

These definitions highlight the abilities a literate person should have in response to real-

life challenges and decisions that are important to the disciplines of science, technology, engineering and mathematics. Such abilities include being able to read and critique texts (e.g., newspaper, medical and food labels, advertisements) related to the discipline, apply disciplinary knowledge to interpret information, and understand and critique disciplinary knowledge as a particular way of inquiry associated with a unique historical, social and cultural context. 
Citation:

Tang, K.S., \& Williams, P.J. (in press). STEM literacy or literacies? Examining the empirical basis of these constructs, Review of Education, doi: 10.1002/rev3.3162

Besides these definitions from the respective professional organisations, it is also necessary to unpack what is literacy itself, as defined and generally agreed within the education community. Literacy is often associated with the ability to read and write printed materials. However, this basic definition is largely obsolete based on a renewed understanding of what is literacy in the $21^{\text {st }}$ century in light of new forms of knowledge mediated and made accessible by digital and multimedia technology (Kress, 2003). The nature of literacy is also shifting in response to rapid social, economic and cultural changes in the globalised knowledge-driven society. Thus, researchers are now redefining literacy along a pluralistic view that acknowledges the diverse sociocultural contexts and practices in multiple communities (Gee, 2004).

A particular useful idea for the purpose of this paper is the concept of disciplinary literacy envisioned by Shanahan and Shanahan (2008). With an awareness there are advanced literacy competencies from every disciplinary area that differ significantly from the basic language skills learned at an early age, Shanahan and Shanahan (2008) conceptualise a pyramid model that depicts an increasing specialisation of literacy development from basic literacy to intermediate literacy to disciplinary literacy. Shanahan and Shanahan's (2008) model of literacy implies that as students progress in their literacy development, they will require more advanced but less generalisable skills and competencies that are demanded in the specialised disciplinary areas.

This theoretical model of literacy has implications to how we conceptualise STEM literacy. In addition, the concept of disciplinary literacy provides a lens for us to examine scientific, mathematical, and technological/engineering literacies along the literacy skills and competencies required in those disciplines, and consequently provides a way to review and organise the diverse literature into meaningful research areas. Based on this conceptualisation, we searched for research journal articles, scholarly books and chapters in ERIC database using search terms like "scien* literacy", "mathematic* literacy", "technolog* literacy" and "engineer* literacy". We then narrowed our search on studies that specifically examined the skill and 


\section{Citation:}

Tang, K.S., \& Williams, P.J. (in press). STEM literacy or literacies? Examining the empirical basis of these constructs, Review of Education, doi: 10.1002/rev3.3162

competency dimensions of literacy. From the search, we distilled 3 major areas that reflect how researchers have examined the notions of literacy within their respective disciplines.

The first area focuses on the disciplinary language that shapes the kind of texts and discourses produced in a discipline. As every discipline has a unique language (including multimodal symbolic systems), the ability to use the disciplinary language is an important aspect of literacy. Norris and Phillips (2003) call this ability the fundamental sense of literacy of being fluent in the resources of text in order to gain access to knowledge (or derived sense of literacy) in the discipline. Texts in this case are defined as "any representational resources or objects that people intentionally imbue with meaning, in the way they either create or attend to the object, to achieve a particular purpose" (Draper \& Broomhead, 2010, p. 28). The second area focuses on the cognitive processes of an individual in reasoning and constructing a critical understanding of the knowledge in the discipline. This aspect of literacy examines the ways of thinking among the expert practitioners and consequently derives levels or categories of competency that can be used as benchmarks to compare and measure students' performances. The third area focuses on the epistemic practices of how people in the discipline produce knowledge or solve problems within the community. An important part of literacy in this area is to understand how the products of a discipline (e.g., theories, models, designs, claims) are generated based on the activities, tools and social context of the community. This understanding is crucial for any literate person to evaluate the validity of the claims and evidence made in the discipline, the public, and the media.

In what follows, we organise the literature on each of the literacies according to the 3 identified areas of disciplinary language, cognitive processes and epistemic practices. For each area, we give a brief description of the research focus and highlight a few landmark studies under each of them. It is important to note that this organisation is not meant to partition the research into isolated and mutually exclusive areas, but rather to serve as heuristic groupings to identify key capabilities that are important for a person to be considered literate in a respective discipline, 


\section{Citation:}

Tang, K.S., \& Williams, P.J. (in press). STEM literacy or literacies? Examining the empirical basis of these constructs, Review of Education, doi: 10.1002/rev3.3162

and consequently to facilitate comparisons among the respective literacies in science, mathematics, technology and engineering.

\section{Scientific Literacy}

\section{Scientific Language}

In science education, the language of science has been widely recognised as an important enabler of science learning and thus an integral component of scientific literacy (Norris \& Phillips, 2003; Yore, Bisanz, \& Hand, 2003). Research in this area has a long history of examining various aspects of scientific language and discourse, such as features of scientific writing, the genres or text structures in science, and science classroom communication (e.g., Tang, 2011; Fang, 2005; Halliday \& Martin, 1993; Lemke, 1990; Wellington \& Osborne, 2001). A key contribution to our understanding of scientific literacy is the insight it provides concerning the challenges that scientific language poses to newcomers in the discipline.

In written texts for instance, Fang (2005) analysed scientific writing and found several unique textual features that are critical to the development of scientific literacy. A common example is the use of technical vocabulary to describe the content of science. Technical terms in science includes names of natural objects and phenomena (e.g., mitochondria, electrolysis) and vernacular words with specialised meanings (e.g., weight, solution, base). Technicality is important for scientists to achieve precision in their naming and categorisation of natural objects and phenomena as well as their construction of taxonomic relationships and theories of the natural world. Another example is abstraction which is the description of events and experiences in terms of abstract entities instead of actions and processes.

Scientific language is not limited to words but also includes other multimodal representations such as diagrams, symbols, graphs, and computerised simulations. As Lemke (2004) argues, the language of science is a unique hybrid consisting of natural language, mathematic systems, and visual representations, all embedded within a material and technological environment in which science is done. Thus, achieving scientific literacy will require the ability 


\section{Citation:}

Tang, K.S., \& Williams, P.J. (in press). STEM literacy or literacies? Examining the empirical basis of these constructs, Review of Education, doi: 10.1002/rev3.3162

to use complex multimodal representations in science, with which many students are not familiar (Lemke, 2000). Recognising this difficulty, many researchers call for the need to help science students develop scientific literacy skills in interpreting and constructing diagrams, charts, figures, and graphic symbols (e.g., Knain, 2006; Tang \& Moje, 2010).

As such, scientific literacy involves learning to use the language and visual representations to think and act as members of a scientific community (Brown, Reveles, \& Kelly, 2005). To become scientifically literate, students need to acquire the discourse of the community through their participation and interactions with knowledgeable others in relevant contexts (Vygotsky, 1986). Building from a Vygotskyan view focusing on the role of language as a mediating tool, researchers have studied students' appropriation of scientific language and discourse over time in the classroom. A study by Mercer et al. (2004) for instance found that a teaching programme designed to improve children's ability to use language in science classrooms has a developmental influence on the students' reasoning ability and scientific understanding.

\section{Scientific Cognitive Processes}

Scientific literacy also involves an individual's capacity in understanding and applying scientific knowledge. This capacity includes a variety of cognitive and metacognitive abilities in the form of comprehension, sense-making, critical thinking and reasoning (Baker, 2003; Norris \& Phillips, 2003). Research in this area has been informed by a cognitive psychological perspective where students' levels of competencies are gauged by a series of performative tasks or tests and subsequently compared with the experts' in the discipline. A key contribution from this research area to our understanding of scientific literacy is the specification - in terms of outcomes or levels of competencies - of what a person can or should be able to do in order to be considered a literate person in the discipline.

As an illustration, Bybee (1999) proposes a hierarchical categorisation of scientific literacy by describing 5 different levels of competencies. The lowest level is scientific illiteracy where an individual lacks the vocabulary, concepts or cognitive capacity to understand a 


\section{Citation:}

Tang, K.S., \& Williams, P.J. (in press). STEM literacy or literacies? Examining the empirical basis of these constructs, Review of Education, doi: 10.1002/rev3.3162

scientific topic or issue. The second level is nominal scientific literacy where an individual recognises a term or topic but having a low level of understanding. This is followed by functional scientific literacy where an individual is able to use scientific words to describe a concept appropriately, but only confined to a limited context such as answering a test question. The next level is conceptual and procedural scientific literacy where an individual is able to relate information and experiences to the major conceptual schemes of science and demonstrate procedural abilities and understanding of the processes of scientific inquiry. The highest level is called multidimensional scientific literacy, which incorporates an understanding of science that extends beyond the concepts and procedures of science to include the history of scientific ideas, the nature and philosophy of science, and the role of science in society.

A similar strand of research that draws on an expert-novice comparison from the cognitive sciences focuses on comprehension strategies. For instance, Shanahan, Shanahan, and Misischia (2011) studied how a group of expert chemists, mathematicians, and historians processed information while they were reading texts in their disciplines, and found several key differences in a number of processes such as graphic information and critical analysis. For example, in terms of treating graphic information, the chemists treated diagrams, graphs, and equations as crucial sources of information equivalent to written language. However, they saw these multimodal sources as different but overlapping information and they often had to cognitively "translate" the information from one source to another.

Critical to the development of literacy in this area is also the role of metacognition, which involves an awareness and regulation of one's own cognitive processes in relation to a particular task. Metacognition has 2 components: metacognitive knowledge and regulation of cognition (Flavell, 1979). Science education research has tended to focus on metacognitive knowledge, which generally consists of declarative knowledge - knowing what knowledge one has, procedural knowledge - knowing how to use the knowledge, and conditional knowledge knowing why, where, and when to use a particular knowledge (Yore \& Treagust, 2006). Much of 


\section{Citation:}

Tang, K.S., \& Williams, P.J. (in press). STEM literacy or literacies? Examining the empirical basis of these constructs, Review of Education, doi: 10.1002/rev3.3162

the research has been applied within the context of reading comprehension (e.g., Baker, 2003) and conceptual understanding (e.g., Blank, 2000). In more recent years, there have been studies of metacognition in the area of science inquiry, reasoning and argumentation (e.g., Zohar \& Barzilai, 2015). In general, there is much consensus among researchers that promoting metacognition in students is an important part of scientific literacy and consequently, science teachers need to incorporate a range of metacognitive strategies in their teaching.

\section{Scientific Epistemic Practices}

Besides language use and cognitive abilities, scientific literacy also requires students' engagement in the epistemic practices related to the consumption, production, communication, and evaluation of knowledge claims in science. Kelly (2008, p. 99) defines epistemic practices as "the specific ways members of a community propose, justify, evaluate, and legitimise knowledge claims within a disciplinary framework". Epistemic practices involve an awareness of the forms of knowledge and ways of knowing in a discipline, and takes into consideration the social context and activities of the discipline, the use of evidence in constructing knowledge or solving problems, and the types of tools and strategies used in the discipline (Kelly, 2011).

A significant development that has led to a growing awareness of the practices of science is the Next Generation Science Standards (NGSS) produced by the National Research Council (2012). The attention towards "practice" was a deliberate shift from "inquiry" which was emphasised in previous curriculum standards (Ford, 2015). This shift highlights the realisation that engaging in scientific inquiry does not require only a set of general skills but also a set of interrelated practices that underpin the epistemology of science in terms of developing theories, building models, and testing knowledge claims. NGSS thus outlines a list of practices that mirror those of professional scientists and engineers, such as constructing explanations, engaging in argument from evidence, and obtaining, evaluating, and communicating information.

Many science education researchers tend to use epistemic practices and scientific practices interchangeably as both terms are closely related. Jiménez-Aleixandre and Crujeiras 


\section{Citation:}

Tang, K.S., \& Williams, P.J. (in press). STEM literacy or literacies? Examining the empirical basis of these constructs, Review of Education, doi: 10.1002/rev3.3162

(2017) conceive of scientific practices as generally a part of epistemic practices in the context of science. However, they also note that some scientific practices, such as measuring quantities or following procedures, are not necessarily epistemic. The important distinction is that epistemic practices deal with the epistemic nature of science, such as how scientific knowledge is generated through a collective human enterprise. In their study, Jiménez-Aleixandre and Crujeiras (2017) propose three important epistemic practices of science that include investigation, argumentation and explanation/modelling. First, the practice of investigation encompasses more than the use of scientific apparatus to conduct experiments, and includes also the planning and design of an empirical investigation in the context of a purposeful inquiry. Second, an important part of building and evaluating knowledge in science involves the practice of argumentation, where knowledge claims are proposed and contrasted based on available evidence in order to be accepted within the scientific community. Engaging in argumentation also involves understanding what can be counted as evidence and how to use evidence to evaluate multiple explanations. Lastly, scientific knowledge construction involves the practice of developing explanations and models about the natural world in terms of how and why it works in a certain way. Scientific explanations and models are based on theories, laws, and evidence, and so an important part of this practice involves knowing the relationship among these terms and how scientists use them to further their work (Tang, 2011).

\section{Mathematical Literacy}

\section{Mathematical Language}

Mathematical literacy involves a mastery of the mathematical language and the ability to read and understand mathematical texts. Mathematics contains a large amount of conventional texts in the form of verbal expressions and word problems used in informal and technical ways (Bass, 2006), as well as multimodal forms of text specific to the discipline, including symbols, notations, drawings, formal proofs and diagrams (Hutchison \& Edelman, 2014). What make these 


\section{Citation:}

Tang, K.S., \& Williams, P.J. (in press). STEM literacy or literacies? Examining the empirical basis of these constructs, Review of Education, doi: 10.1002/rev3.3162

texts particularly unique and distinct from ordinary language is their emphasis on accuracy and precision. In fact, many researchers have argued that the demand for precision by mathematicians in their problem solving and communication have led to the historical evolution of a precise mathematical language and symbol system (Lemke, 2003; O'Halloran, 2005).

The language of mathematics is further characterised by Sfard (2007) in four text features: mathematical words, visual mediators, narratives, and routines. Mathematical words are specialised terminology developed and used with precise meanings related quantities and shapes (e.g., square root, hypotenuse). Visual mediators are symbolic non-verbal artifacts such as formulae, graphs, drawings and diagrams created to facilitate mathematical thinking and communication. Narratives are strings of words and symbols that describe mathematical relations and they can be judged as true or false. They function somewhat like the "syntax" of mathematics. Common examples include definitions, axioms, proofs and theorems. Lastly, routines are repetitive and well-defined patterns of texts that are shared and recognisable in mathematics. This is a broader category that encompasses mathematical words, visual mediators and narratives arranged in some kind of regularities and repeated patterns, such as numerical calculations, problem solving procedures, and manipulations of mathematical objects. Routines form the basis of mathematical reasoning and argumentation (Hillman, 2014).

Mathematical language provides a shared resource for collective activity and communication within a community of practice. In the sense that the use of mathematical language brings certain groups of people together can exclude others, it can be argued that the membership of a mathematics community rests upon the use of the language (Sfard, 2007). By acquiring the community's language, students will be able to internalise the language and think like members within the community. Therefore, a part of mathematics literacy involves acquiring this "ability to function seamlessly within a given community of practice among mathematicians" (De Lange, 2003, p. 72). 
Citation:

Tang, K.S., \& Williams, P.J. (in press). STEM literacy or literacies? Examining the empirical basis of these constructs, Review of Education, doi: 10.1002/rev3.3162

\section{Mathematical Cognitive Processes}

The literature on mathematical literacy from a cognitive perspective follows a similar approach to that of scientific literacy. Many studies focus on the outcomes or levels of competencies in terms of what a person can or should be able to do in order to be considered a literate person in mathematics. For instance, adapting Bybee's (1999) hierarchical categorisation of scientific literacy, Kaiser and Willander (2005) distinguish five levels of mathematical literacy. Mathematical illiteracy indicates a lack of basic mathematical concepts and methods. Nominal literacy is characterised by a surface understanding of a mathematical term or topic with some naïve explanations and misconceptions. Functional literacy implies an application of mathematical methods for simple problem solving, but limited within familiar situations and contexts. Conceptual and procedural literacy involves an understanding of central mathematical concepts (e.g., function, derivative) and their relationships under a coherent conceptual scheme. Lastly, mathematical multidimensional literacy, involves a holistic understanding of the historical and social dimensions of mathematics and an appreciation for mathematics as an enterprise and culture. Although these levels of mathematical literacy are very similar to those of Bybee's levels of scientific literacy, Kaiser and Willander (2005) argued that mathematical and scientific literacies are distinct due the different epistemological status of science and mathematics.

Research focusing on the expert-novice comparison in mathematics examines the cognitive strategies employed by mathematicians as they read and process information. Shanahan, Shanahan, and Misischia (2011) studied and compared a group of mathematicians with chemists and historians. An interesting contrast was the way mathematicians treated multimodal sources of representation differently. While chemists saw these multimodal sources as different and often had to compare and translate information from one source to another, mathematicians saw no distinction between written texts and equations, and they interpreted them together in a unified manner. Furthermore, in terms of critique, mathematicians paid more attention to 


\section{Citation:}

Tang, K.S., \& Williams, P.J. (in press). STEM literacy or literacies? Examining the empirical basis of these constructs, Review of Education, doi: 10.1002/rev3.3162

accuracy and less to credibility of the source as opposed to chemists and historians who examined the plausibility and congruence of the given information with other evidence.

Metacognition is another area that has received much attention in mathematics education, and many researchers have made the connection between the use of metacognitive strategies to the achievement of mathematical literacy (e.g., Chen \& Chiu, 2016; Kramarski \& Mizrachi, 2006). Using the data from 2009 PISA, Kaur and Areepattamannil (2012) found that metacognitive learning strategies for reading have a positive correlation with the adolescents' performance in mathematical literacy (as measured by the test items in PISA) in Australia and Singapore. Consequently, there has been a push to develop metacognition strategies in mathematics education. A popular strategy was adapted from Polya's (1973) problem-solving heuristic consisting of (i) comprehending the problem, (ii) planning the solution, (iii) implementing the plan, and (iv) looking backward to evaluate. Each heuristic involves a series of questions that students need to ask of themselves in solving mathematical problems. By learning this problem solving strategy, the aim is for the students to develop metacognitive thinking and mathematical literacy (Hutchison \& Edelman, 2014).

\section{Mathematical Epistemic Practices}

There have not been many studies that explicitly examine the epistemic practices involved in mathematical literacy. One notable report was prepared by an expert panel of mathematicians and education researchers for the Office of Educational Research and Improvement (OERI) in the U.S. (Ball, 2003). The report outlines a proposed strategic research and development program with a priority to teach what the panel calls "mathematical practices". Mathematical practices extend beyond mathematical knowledge to focus on the mathematical know-how and specific things that mathematicians and mathematics users do. As a distinction from "skills" that tend to imply a coordinated set of actions, the panel chose the term "practices" as a broader construct to reflect the interrelated activities that involve common tools, knowledge base and skills. Mathematical practices are central to the way people approach mathematical 


\section{Citation:}

Tang, K.S., \& Williams, P.J. (in press). STEM literacy or literacies? Examining the empirical basis of these constructs, Review of Education, doi: 10.1002/rev3.3162

problems and work with the tools and ideas developed in the discipline, and as such, they relate to the consumption, production, communication and evaluation of mathematical knowledge.

The report further recommends three core mathematical practices that are relevant for a functional citizenry: representation, justification and generalisation. Representation involves the choices one makes in expressing mathematical ideas in its multimodal forms in relation to the purpose and context of use. Justification involves knowing how mathematical knowledge is validated and established as common knowledge. This includes the ability to understand and construct proofs, which are formal justifications set by mathematicians as well as more general reasoning to support the validity of a mathematical claim in everyday context. The third mathematical practice involves making generalisation from a set of data to derive statements or conclusions that transcend beyond the specific data or observations. A defining characteristic of mathematical generalisation is the search for underlying patterns, structures and relationships to hypothesise and test any general conclusion.

\section{Technological/Engineering Literacy}

For the purposes of this discussion, technology and engineering have been combined and discussed as a common literacy. This is not to deny differences between these two areas, or the validity of a hierarchical relationship (for example, engineering is a subset of technology), but to recognise the epistemic and procedural similarities. The epistemology of both areas is pragmatic, related to the common procedural focus of designing solutions to problems. The technology or engineering body of knowledge that is relevant at any particular time and place is determined by the nature of the problem for which a solution is being designed. Procedurally, design is recognised as the methodology of both disciplines. In addition, in a school context, when Engineering is taught it is generally within the Technology Learning Area. 


\section{Citation:}

Tang, K.S., \& Williams, P.J. (in press). STEM literacy or literacies? Examining the empirical basis of these constructs, Review of Education, doi: 10.1002/rev3.3162

\section{Technological/Engineering Language}

Engagement with technology is an unavoidably central characteristic of people's personal and professional lives. This engagement goes beyond the mere use of technology to participate within a technological milieu which is both personally reactionary, professionally meaningful and socially deterministic. Thus, a level of technological multiliteracy is fundamental to effective engagement and the consequent design of an appropriate social future (Williams, 2014).

Technological multiliteracy is founded upon multimodal forms of communication through language. The development of digital forms of language now render technological / engineering literacy essentially multimodal - resulting in consequent discussions of the concept of multiliteracy. Underlying this perspective is a view of (multi)literacy as both a construct of, and a cultural tool for the members a social group to achieve both individual goals and group purposes (Lima, 1995; Gee, 2001), therefore relating to the mechanism which enables the social group (technologists and engineers) to function as a working community, and at the same time to achieve a level of multiliteracy which is more broadly culturally and socially significant.

The language of the social community, in the case of technology and engineering, becomes the mechanism to guide the resolution of problems and the production of designs (Vygotsky \& Cole, 1978). The language of technology and engineering is not limited to written texts, but encompasses sketches, diagrams, drawings bills of material, project management diagrams, schematics, etc., which are in most cases digital (Johri, Roth, \& Olds, 2013). For instance, engineers often use computer-aided design (CAD) to render 3D objects through an oblique or axonometric projection, which is at odds with the perspective projection commonly found in visual arts (Tang, 2013). As the language is used and internalised, it becomes the 'cognitive frame that makes the world meaningful to us, and furthermore makes our actions more meaningful to the world' (Atman, Kilgore and McKenna, 2008, p. 310). This internalisation of language is a gradual process, and reflects an integration into the community of practice (Wenger, 


\section{Citation:}

Tang, K.S., \& Williams, P.J. (in press). STEM literacy or literacies? Examining the empirical basis of these constructs, Review of Education, doi: 10.1002/rev3.3162

1998) which has three dimensions: mutual engagement, joint enterprise, and shared repertoire. Language plays a key role in each of these dimensions of community.

For instance, research by Atman, Kilgore and McKenna (2008) indicated that students do progress towards membership in a community of practice by acquiring the community's language, and come to frame design problems using the logic of this language. As students progressed through an engineering course, their use of language progressively aligned with that of experts, and their use of language increasingly shaped student responses to design scenarios.

\section{Technological/Engineering Cognitive Processes}

Technologists and engineers begin their cognitive activities as an outcome of the examination of design tasks - imagining, memorising, representing, problem solving, planning, and so on. There are qualitative differences in these types of cognitive skills applied to design problems. Some are automatic; they are applied with no intentional effort which makes performance in these areas fluent and effortless. Other skills are more controlled and require focussed attention and are prone to error. They are flexible in application, however, and can be used in a wide variety of design contexts.

Researchers have investigated the various types of cognitive processes involved in technological/engineering literacy. For example, in an analysis of technology/engineering students engaged in design based learning, Wells (2016) identified cognitive abilities through the classifications of declarative (knowing that), procedural (knowing how), schematic (knowing why), and strategic (knowing when and where) knowledge. In his systematic approach to engineering design, Pahl et al. (2007) identified conceptual design and embodiment design as two crucial phases in the creation of technical products and systems. Early technology education curriculum in both England and Australia also characterised the design and problem solving process as consisting of: designing, making and appraising (Williams, 1992). However, in the practical context of technology and engineering, cognitive skills cannot stand in isolation from skills in the affective and motor domains, and the danger with such classifications is that each 


\section{Citation:}

Tang, K.S., \& Williams, P.J. (in press). STEM literacy or literacies? Examining the empirical basis of these constructs, Review of Education, doi: 10.1002/rev3.3162

category be perceived as discrete and sequential, as though you can first design and then make, or think and then do, or conceive of a design and then embody the design. Caution regarding this false dichotomy between cognition and practice results in a recognition that the application of cognition is pervasive throughout all aspects of technological/engineering activity.

There are many conceptions of this relationship between thinking and doing, separating cognitive and practical skills. In the development of intelligence, Piaget proceeds from the concrete to the abstract, but always retains a strong cognitive basis for all skills. In recounting his transfer from a Washington think tank to a motor bike repair shop, Matthew Crawford (2009) elaborates on the essentiality of cognition informing practice, and in his own experience, he often found manual work more engaging intellectually than 'knowledge work'.

Pahl et al (2007) describes these cognitive processes which inform practice as a semantic network of nodes (knowledge) and connections (relationships), which can proceed intuitively (with flashes of inspiration) or discursively (consciously). Literacy is related to the sophistication of the epistemic structure (logic of applied knowledge) which continues to develop over time as new contexts and problems are experienced. As these contexts and problems occur, for professionals, in particular areas of technology and engineering, the semantic structure becomes shaped by that particularity, resulting in a unique form of professional technological literacy.

In the technological/engineering design context, where a range of specific variables (cost, functionality, aesthetics, ease of use, client specifications) are continually competing for dominance, and the design process itself is complex and iterative, the application of metacognitive processes are essential in continually pushing toward design resolution. Some research has indicated that novice designers apply different cognitive strategies to design problems than more experienced designers. The experienced designers take a more immediate overview of the task and employ metacognitive strategies sooner and more naturally. Whereas novice designers, at the beginning, focus on design details and the identification of design difficulties (Liang et al., 2007). Baxt (1995) identified six metacognitive processes: problem 


\section{Citation:}

Tang, K.S., \& Williams, P.J. (in press). STEM literacy or literacies? Examining the empirical basis of these constructs, Review of Education, doi: 10.1002/rev3.3162

definition, planning, strategy selection, flexibility (of strategy use), evaluating, and checking and monitoring. So developing literacy in this sense also relates to the uninhibited application of metacognitive processes to the range of cognitive activity brought to bear on a design problem.

\section{Technological/Engineering Epistemic Practices}

The epistemic practices of technology and engineering could be positioned as representing the fundamental nature of literacy in this area because of its dynamism. Dakers (2014) holds that "due to the complexity of the technologically textured world we inhabit, a world that is emergent and in a constant state of change, the concept of technological literacy can only ever be expressed in terms of an ongoing process" (p. 2). In this sense the process is positioned as a central element of the nature of technological and engineering literacy, and consequently becomes the practice which forms the epistemology of technology/engineering.

If the epistemology of technology and engineering is formed through its practice, then it is relevant to enquire regarding the nature and the goal of the practice. In a general sense, the goal of technological and engineering practice is to design a solution to a problem or address a need (McCormick, Murphy \& Hennessy, 1994). The goal or need maybe social (a system for the effective movement of people), institutional (a bridge) or personal (a living space). The process to achieve the goal may include clarifying the problem, developing parameters, exploring options, modelling, designing solutions, and so on.

The design activity of technology and engineering has been characterised as dealing with 'wicked' problems (Burge \& McCall, 2015). For some researchers (Farrell \& Hooker, 2013), this characterisation has been for the purpose of identifying the cognitive character of such problems, but in this case we see it as a mechanism that characterises the epistemic practices of technology and engineering. Wicked problems have no definitive formulation, they do not have dichotomous solutions (e.g., good or bad, true or false), they are each unique, they are symptoms of other problems, and the definition of the problem determines its resolution. Given these characteristics, it is not possible to pre-determine the epistemological nature of the requirements to solve the 


\section{Citation:}

Tang, K.S., \& Williams, P.J. (in press). STEM literacy or literacies? Examining the empirical basis of these constructs, Review of Education, doi: 10.1002/rev3.3162

problem. There is no pre-existing body of knowledge which can be applied to a wicked problem the nature of the problem itself determines the epistemic practice.

Despite the difficulty of predicting the nature of epistemic practice in technology and engineering, Cunningham and Kelly (2017) reviewed the literature and identified 16 practices of engineering in four broad categories, namely engineering in social contexts, uses of data and evidence to make decisions, tools and strategies for problem solving, and finding solutions through creativity and innovation. Some of the epistemic practices include: Developing processes to solve problems, innovating processes, methods, and designs, applying mathematics and science knowledge to problem-solving, constructing models and prototypes, and making evidence-based decisions. The reality of solving a problem draws selectively on these types of practices.

Despite the often interchangeable use of the terms design and problem solving, some researchers differentiate between them (Pahl et al, 2007), and classify problems as analytic tasks (Eggert, 2005) and a technology or engineering task as distinct from a problem, and so involves a different type of process. Pahl et al (2007) generalise the relationship between the application of knowledge through a process to solve a problem by identifying knowledge as having an epistemic structure when it is transferred from the general factual knowledge to a particular problem. In a context of formative technology education curriculum, Williams (2000) proposed multiple conceptions of models of practice in the broad categories of design, problem solving, invention, systems and manufacturing; involving specific cognitive skills in evaluation, communication, modelling, generating ideas, research and investigation, producing and documenting.

Referring to the nature of technological and engineering literacy then, we affirm Dakers (2014) perception that literacy is essentially an ongoing process. As every problem or need that is addressed is the result of a sequence of unique epistemic practices, literacy becomes a way of acting (Ingerman \& Collier-Reed, 2011). Expertise (or enhanced literacy) is developed through repeatedly acting in technology and engineering contexts, building experience in the selective application of epistemic practices. 
Citation:

Tang, K.S., \& Williams, P.J. (in press). STEM literacy or literacies? Examining the empirical basis of these constructs, Review of Education, doi: 10.1002/rev3.3162

\section{Comparison of Literacies}

Based on the review of the literature, we found similar trends and lines of inquiry in the way scientific, mathematical, technological/engineering literacies have been conceptualised and studied by researchers in their respective communities. These similarities offer a common ground that could be used as a basis for defining a collective STEM literacy across the disciplines. At the same time, there are also many differences, particularly in the epistemic domain, in the specific nature of each discipline and the way each discipline has been researched that distinguish the various disciplinary literacies. Table 2 presents a summary of these similarities and differences. It is important to note that Table 2 shows only a limited non-exhaustive list based on our literature review.

Table 2.

Summary of Similarities and Differences among the S.T.E.M. Literacies

\begin{tabular}{|c|c|c|c|}
\hline & Science Literacy & $\begin{array}{l}\text { Mathematics } \\
\text { Literacy }\end{array}$ & $\begin{array}{l}\text { Technological/ } \\
\text { Engineering Literacy }\end{array}$ \\
\hline Similarities & \multicolumn{3}{|c|}{$\begin{array}{l}\text { The creation, use and conversion of codified multimodal representatic } \\
\text { The mastery of common visual resources such as annotated diagrams } \\
\text { and geometric drawings } \\
\text { The application of cognitive and metacognitive strategies involving } \\
\text { problem identification, planning, evaluation and self-monitoring }\end{array}$} \\
\hline $\begin{array}{l}\text { Differences } \\
\text { in } \\
\text { disciplinary } \\
\text { language }\end{array}$ & $\begin{array}{l}\text { Highly specialised } \\
\text { and contextualised } \\
\text { use of representations } \\
\text { (e.g., Feynman } \\
\text { diagrams) }\end{array}$ & $\begin{array}{l}\text { Highly specialised } \\
\text { and contextualised } \\
\text { use of representations } \\
\text { (e.g., Hasse diagrams) }\end{array}$ & $\begin{array}{l}\text { Highly specialised and } \\
\text { contextualised use of } \\
\text { representations (e.g., } \\
\text { Architecture } \\
\text { blueprints) }\end{array}$ \\
\hline $\begin{array}{l}\text { Differences } \\
\text { in cognitive } \\
\text { processes }\end{array}$ & $\begin{array}{l}\text { Metacognitive } \\
\text { emphasis on level of } \\
\text { understanding and } \\
\text { comprehension }\end{array}$ & $\begin{array}{l}\text { Metacognitive } \\
\text { emphasis on level of } \\
\text { understanding and } \\
\text { problem-solving }\end{array}$ & $\begin{array}{l}\text { Metacognitive } \\
\text { emphasis depending on } \\
\text { design context, and } \\
\text { more focus on doing } \\
\text { and practical skills }\end{array}$ \\
\hline $\begin{array}{l}\text { Differences } \\
\text { in epistemic } \\
\text { practices }\end{array}$ & $\begin{array}{l}\text { Orient towards both } \\
\text { specific and universal } \\
\text { forms of knowledge, } \\
\text { by building } \\
\text { generalisable } \\
\text { claims/theories from }\end{array}$ & $\begin{array}{l}\text { Orient towards } \\
\text { universal forms of } \\
\text { knowledge, involving } \\
\text { abstract } \\
\text { representations, } \\
\text { formal justifications }\end{array}$ & $\begin{array}{l}\text { Orient towards specific } \\
\text { forms of knowledge, } \\
\text { involving wicked } \\
\text { problems, social } \\
\text { contexts, needs-based }\end{array}$ \\
\hline
\end{tabular}


Tang, K.S., \& Williams, P.J. (in press). STEM literacy or literacies? Examining the empirical basis of these constructs, Review of Education, doi: 10.1002/rev3.3162

\begin{tabular}{lll}
$\begin{array}{l}\text { and to account for } \\
\text { observable } \\
\text { phenomena }\end{array}$ & $\begin{array}{l}\text { mathematical } \\
\text { generalisation }\end{array}$ & $\begin{array}{l}\text { goals and ongoing } \\
\text { processes }\end{array}$ \\
\hline
\end{tabular}

In the area of disciplinary language, researchers have mostly adopted the position that language serves as a prerequisite cultural tool for existing members as well as newcomers to function and develop their expertise within a community of practice. A common theme is the attention to multimodal representations, which are not only ubiquitous in all the STEM disciplines, but are also central to the framing of knowledge and practice within each discipline. In particular, the creation and use of diagrams (e.g., charts, sketches, schematics, blueprints) and the conversions of these diagrams from and into other representations - written texts, symbolic expressions, and physical artefacts - seems to be a common thread across the disciplines. A key characteristic of these diagrams is that they are often codified with standards and conventions specific to the way the diagrams are produced and interpreted. For newcomers and the general public, these specialised conventions may give the STEM disciplines an appearance of technicality and make the disciplinary language less accessible.

A number of conventionalised diagrams are also commonly used across the STEM disciplines; for example, annotated diagrams and geometric drawings (involving scale, angle and measurement) are found in all of the STEM areas. Some specialised diagrams, such as circuit and vector diagrams, are also shared visual resources used in multiple disciplines related to electricity and dynamics. Some researchers (e.g., Nathan et al., 2013) have argued that these representations serve as common tools that allow STEM-related professionals to communicate and work across different communities. Thus, the mastery and use of these diagrams constitute a common literacy skill that is required in STEM. However, it is important not to overgeneralise this aspect as there are many other visual representations that are highly unique and specific to a particular field and are rarely used or learned outside a particular community (e.g., phylogenetic tree in biology, architectural blueprints in construction). Furthermore, the meaning and function of a representation also depend on the social context in which it is used. For instance, a geometric 


\section{Citation:}

Tang, K.S., \& Williams, P.J. (in press). STEM literacy or literacies? Examining the empirical basis of these constructs, Review of Education, doi: 10.1002/rev3.3162

drawing may be used by a mathematician to proof some trigonometric relationships while the same drawing is used by an engineer to estimate the dimensions of a design (for examples, see van der Wal, Bakker, \& Drijvers, 2017). Some studies have compared the similarities and differences in the visual representations used in science, technology, engineering and mathematics (e.g., Nathan et al., 2013; Tang, 2013), but more is needed to further specify the common visual skill set required in STEM literacy.

In the area of cognitive ability, there seems to be a common emphasis in examining the cognitive activities of experts and distilling a list of competencies that are relevant to the discipline. Researchers in this area have found not only a number of qualitative differences between novices and experts, but also that experts tend to employ more metacognitive strategies in performing related tasks. As metacognition has been found to be important in learning the concepts and processes involved in the STEM disciplines, the use of metacognitive processes should be emphasised as a common skill set in STEM literacy. In particular, metacognitive processes that involve some aspects of problem identification, planning, evaluation and selfmonitoring are generally shared across science, technology/engineering and mathematics.

However, there are also specific differences in the nature of the cognitive and metacognitive processes valued across the STEM disciplines. Judging by the research work in the literature, there is a high emphasis on deep understanding and comprehension in scientific and, to some extent, mathematical literacy. Both areas have also defined literacy in terms of a broader and more sophisticated level of understanding (e.g., Bybee, 1999; Kaiser \& Willander, 2005). For technology and engineering, there is a recognition that literacy is not solely about knowing and thinking, but also includes elements of doing. As such, there is comparatively more research emphasis on design and practical skills. Moreover, the use of metacognition tends to be applied in a design context and focus on having a more conscious deliberation of the complex range of cognitive activities involved in a task. The differences in the range of cognitive and metacognitive processes across the STEM disciplines can be attributed to either differences in the 


\section{Citation:}

Tang, K.S., \& Williams, P.J. (in press). STEM literacy or literacies? Examining the empirical basis of these constructs, Review of Education, doi: 10.1002/rev3.3162

nature of the discipline or differences in the research agenda among various research communities, or a combination of both.

As for epistemic practices, we found mostly differences across the STEM disciplines due to the varying emphasis of what is considered and valued as knowledge in each discipline. An interesting contrast is seen in the type of knowledge that is emphasised, which ranges along a continuum from general to specific knowledge. On one end, mathematics espouses the most general form of knowledge and this explains the universal-oriented nature of its epistemic practices to use abstract representations, derive justifications (e.g., proofs) and make mathematical generalisation. Science sits somewhere in the middle as it deals with observable phenomena (through investigations), and at the same time, makes generalisable claims and builds overarching models and explanations to account for those phenomena. On the other end, the epistemic practices of technology and engineering are context-specific due to the goal-oriented and socially contextualised nature of the disciplines.

As we compare the various literacies, it is necessary to point out some limitations in our approach. First, the nature of each STEM discipline clearly involves more than disciplinary language, cognitive processes and epistemic practices. Nonetheless, the categorisation of the literature into these 3 areas reflect how researchers have conceptualised each of the literacies across the STEM disciplines. On a broad level, this categorisation is useful way to clarify the meaning of STEM education and the complex and multi-faceted issues surrounding it. On a more specific level, it is always possible to split the boundaries further to capture a wider range of epistemological and ontological issues in each discipline that are beyond the categorisation of language, cognition and practices discussed in this paper. This limitation also extends to the discussion of technological and engineering literacies as one common literacy. Although there are fine differences between technology and engineering, there are more similarities than differences when it comes to the comparison with science and mathematical literacies in the contemporary context of STEM education. As a broad exploration of the concept of STEM literacy, the 


\section{Citation:}

Tang, K.S., \& Williams, P.J. (in press). STEM literacy or literacies? Examining the empirical basis of these constructs, Review of Education, doi: 10.1002/rev3.3162

limitations in this paper do not invalidate our goal of ascertaining the research validity of a unitary STEM literacy. Instead, these limitations could provide an initial basis as well as the delineating scope for future research to continue where we left off in this review and examine the specific nuances that differentiate the various literacies.

\section{Discussion: STEM Literacy or STEM Literacies?}

From the comparison, we can make a number of inferences concerning the validity and usefulness of STEM literacy as a construct. First, due to several commonalities in the language and cognitive aspects of the disciplines, there is some basis for postulating a unitary STEM literacy that reflects shared skills required in all the STEM disciplines. Based on current research, these skills involve a familiarity with he technical language and representations as well as the common cognitive and metacognitive processes involved in the disciplines. It is reasonable that the skills introduced or learned in one discipline can be applied and reinforced (with careful pedagogical consideration) in another discipline, as well as learning these overlapping skills an integrated STEM approach. In this context, the notion of STEM literacy is useful in capturing the common set of skills that need to be emphasised in the teaching and learning of the STEM areas. This will also inform the identification of learning outcomes in a STEM curriculum and pedagogical guidelines for teachers to design their lessons. According to our review, current research in the respective STEM disciplines has to some extent identified several skills that are overlapping, although we also need to acknowledge that the research (and this review) so far has not been comprehensive in covering many areas. More research in identifying common literacy skills across the STEM disciplines will further strengthen and substantiate the validity of STEM literacy as an educational construct, rather than just a political rhetoric.

Due to the differences identified across the disciplines, we need to acknowledge the limited application of STEM literacy. Based on the common set of skills we found from the literature, we argue that STEM literacy is more applicable for the broad purpose of improving STEM-related knowledge and skills for everyone. This is aligned with a "STEM for all" focus of 


\section{Citation:}

Tang, K.S., \& Williams, P.J. (in press). STEM literacy or literacies? Examining the empirical basis of these constructs, Review of Education, doi: 10.1002/rev3.3162

increasing the literacy of the general population in terms of understanding the issues, making informed choices, and participating in civic discussions related to STEM. As Fisher and Frey (2015, p.86) have elegantly argued, "all students - whether or not they pursue careers in science, technology, engineering, and math — will be consumers of news and information on STEM issues that will directly affect their lives". To be able to critique such news and information will require the kind of language and cognitive skills we have reviewed from the STEM disciplines.

In contrast to STEM literacy, the differences among the disciplines may call for an additional construct - "STEM literacies" - to reflect the specific skills required in each disciplinary area. According to a position paper on literacy by $\operatorname{UNESCO}(2004$, p.6), the emphasis on the plurality of literacy "recognises that there are many practices of literacy embedded in different cultural processes, personal circumstance and collective structures". Therefore, this distinction from the singular STEM literacy is necessary to highlight some of the skills that are unique in a particular discipline, and therefore not applicable in all the other disciplines. These include the diverse skills related to interpreting, critiquing, and creating the variety of texts found in multiple communities and the different kind of cognitive and metacognitive processes used across the disciplines. Just as important is the distinctively different epistemic practices, which range from general to context-specific, that address the nature of knowledge valued in the disciplines. As such, the notion of STEM literacies - emphasising the varying linguistic, cognitive and epistemic dimensions of the disciplines - is more appropriate in capturing the wide range of skills and emphasis related to specialised professions.

The distinction between STEM literacy and STEM literacies draws some parallel to the framework of disciplinary literacy proposed by Shanahan and Shanahan (2008). In the early years of schooling, STEM literacy provides a foundational base that will be required for any STEMrelated study and work in the future. At a higher level, these skills begin to become specialised and differentiated. As such, students will be required to learn and master a different set of skills 


\section{Citation:}

Tang, K.S., \& Williams, P.J. (in press). STEM literacy or literacies? Examining the empirical basis of these constructs, Review of Education, doi: 10.1002/rev3.3162

specific to each discipline. In this sense, each of the S.T.E.M. literacies is a form of disciplinary literacy that needs to be learned within the respective discipline.

However, it is important to recognise that the parallel with Shanahan and Shanahan's (2008) literacy framework cannot be stretched too far as their view of a linear progression from generic to disciplinary literacy may be too rigid to take into account the interdisciplinary connections within the STEM fields. As an integration of STEM, STEM literacy is more than the sum of its parts. What STEM literacy provides, that the independent disciplines do not, is also a holistic understanding of how concepts, processes and ways of thinking can be integrated and applied to the design of a solution to a real-world problem. These 'wicked' problems often require an interdisciplinary approach rather than a singular disciplinary approach.

Therefore, STEM literacy should not be conceptualised as merely a set of basic skills required in the STEM areas but as a continuum that interweaves with the notion of S.T.E.M. literacies, as represented in Figure 1. Complete literacy is never achieved, either in a specific discipline or in STEM. Any individual is always developing their level of literacy, in alignment with their profession, interests, inclinations and personality. Even though, at the conclusion of formal education, literacy developed through instruction will cease, individuals all continue to develop their literacy through professional engagement and life experiences. Figure 1 also represents the integrated path of literacy development, between the individual S.T.E.M. literacies and STEM literacy, as indicated by this literature review. The boundaries between the development of these literacies is permeable, and all individuals are at different points on the spectrum as they develop towards being literate. 
Citation:

Tang, K.S., \& Williams, P.J. (in press). STEM literacy or literacies? Examining the empirical basis of these constructs, Review of Education, doi: 10.1002/rev3.3162

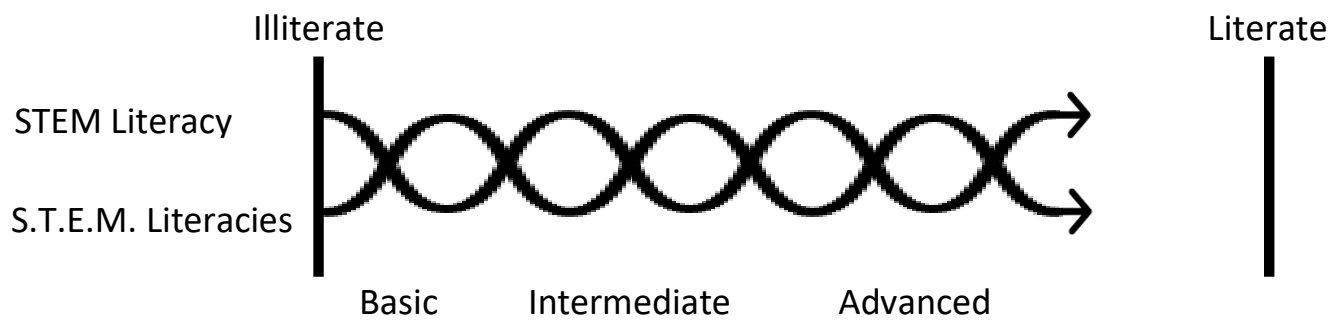

Figure 1. STEM literacy and S.T.E.M. literacies.

To conclude, this paper indicates there is a research basis for the construct of STEM literacy as an intersection and integration of the skills and practices required in all STEM disciplines. At the same time, there is also sufficient research evidence to differentiate the specific skills and practices that are found in all of the STEM disciplines, and thus justify the need to define and distinguish S.T.E.M. literacies as the representation of all the relevant literacies (e.g., scientific, technological, engineering, mathematical literacy). Given the current rhetoric on STEM literacy, it is important that this construct be substantiated by the existing knowledge base and research evidence found in the literature. Furthermore, there needs to be more clarity in how the term STEM literacy is used for policy, research, curriculum and instruction on STEM education. Our findings in this review present a step toward this direction.

\section{References}

Atman, C., Kilgore, D. \& McKenna, A. (2008). Characterizing design learning: a mixed methods study of engineering designers use of language. Journal of Engineering Education, 97(3), p. 309-326. DOI: $10.1002 / j .2168-9830.2008 . t b 00981 . x$

Baker, L. (2003). Reading comprehension and science inquiry: Metacognitive connections. In E. W. Saul (Ed.), Crossing borders in literacy and science instruction: Perspective on theory and practice (pp. 239-257). Newark, DE: National Science Teachers Association.

Ball, D. (2003). Mathematical proficiency for all students: Towards a strategic research and development program in mathematics education. Santa Monica, C.A.: Rand.

Bass, H. (2006). What is the role of oral and written language in knowledge generation in mathematics? Toward the improvement of secondary school teaching and learning. Integrating language, literacy, and subject matter. Ann Arbor, MI; University of Michigan Press.

Baxt, S.V. (1995). Metacognition gets personality: a developmental study of the personality correlates of metacognitve functioning. Carleton University, Ottawa.

Blank, L. M. (2000). A metacognitive learning cycle: A better warranty for student understanding? Science Education, 84, 486-506. 
Citation:

Tang, K.S., \& Williams, P.J. (in press). STEM literacy or literacies? Examining the empirical basis of these constructs, Review of Education, doi: 10.1002/rev3.3162

Brown, B. A., Reveles, J. M., \& Kelly, G. J. (2005). Scientific literacy and discursive identity: A theoretical framework for understanding science learning. Science Education, 89(5), 779-802

Bybee, R. W. (1999). Toward an understanding of scientific literacy. In K. Comfort (Ed.), Advancing Standards for Science and Mathematics Education: Views From the Field. Washington, D.C.: American Association for the Advancement of Science.

Chalmers, C., Carter, M., Cooper, T., \& Nason, R. (2017). Implementing "Big Ideas" to Advance the Teaching and Learning of Science, Technology, Engineering, and Mathematics (STEM). International Journal of Science and Mathematics Education, 15(1), 25-43. doi:10.1007/s10763-017-9799-1

Chen, C.-H., \& Chiu, C.-H. (2016). Collaboration Scripts for Enhancing Metacognitive Selfregulation and Mathematics Literacy. International Journal of Science and Mathematics Education, 14(2), 263-280. doi:10.1007/s10763-015-9681-y

Crawford, M. (2009). Shop class as soulcraft: an inquiry into the value of work. New York: The Penguin Press.

Cunningham, C. M., \& Kelly, G. J. (2017). Epistemic Practices of Engineering for Education. Science Education, 101(3), 486-505. doi:10.1002/sce.21271

Dakers, J. (Ed.) (2014). New frontiers in Technological Literacy. New York: Palgrave Macmillan.

DeCoito, I. (2016). STEM Education in Canada: A Knowledge Synthesis. Canadian Journal of Science, Mathematics and Technology Education, 16(2), 114-128. doi:10.1080/14926156.2016.1166297

De Lange, J. (2003). Mathematic for literacy. In B. L. Madison \& L. A. Steen (Eds.), Why Numeracy Matters for Schools and Colleges (pp. 75-89): The National Council on Education and the Disciplines.

Draper, R. J., \& Broomhead, G. P. (2010). (Re) imagining content-area literacy instruction. New York: Teachers College Press.

Eggert, R. (2005) Engineering Design. New Jersey: Pearson Prentice Hall.

Elshof, L. (2014) Eco-technological literacy for resiliency. Ch 6 in J. Dakers (Ed.) New frontiers in Technological Literacy (pp. 91-102). New York: Palgrave Macmillan.

English, L. D. (2017). Advancing Elementary and Middle School STEM Education. International Journal of Science and Mathematics Education, 15(1), 5-24. doi:10.1007/s10763-017-9802-x

Fang, Z. (2005). Scientific literacy: A systemic functional linguistics perspective. Science Education, 89(2), 335-347.

Fisher, D., \& Frey, N. (2015). STEM for Citizenship. Educational Leadership, 72(4), 86-87.

Flavell, J. H. (1979). Metacognition and cognitive monitoring: A new area of cognitivedevelopmental inquiry. American Psychologist, 34, 906-991.

Ford, M. J. (2015). Educational Implications of Choosing "Practice" to Describe Science in the Next Generation Science Standards. Science Education, 99(6), 1041-1048. doi:10.1002/sce.21188

Gee, J. P. (2001). An introduction to discourse analysis theory and method. London; New York: Routledge.

Gee, J. P. (2004). New times and new literacies: Themes for a changing world. In A. F. Ball \& S. W. Freedman (Eds.), Bakhtinian perspectives on language, literacy, and learning (pp. xi, 349 p.). Cambridge, UK; Cambridge University Press.

Halliday, M. A. K., \& Martin, J. R. (1993). Writing science : literacy and discursive power. Pittsburgh: University of Pittsburgh Press.

Hillman, A. M. (2014). A literature review on disciplinary literacy: How do secondary teachers apprentice students into mathematical literacy? Journal of Adolescent \& Adult Literacy, 57(5), 397-406.

Hutchison, L., \& Edelman, J. (2014). Literacy in the mathematics classroom. In P. Smagorinsky (Ed.), Teaching Dilemmas and Solutions in Content-Area Literacy (pp. 57-80). Thousand Oaks, CA: Sage.

Jiménez-Aleixandre, M. P., \& Crujeiras, B. (2017). Epistemic practices and scientific practices in science education. In K. S. Taber \& B. Akpan (Eds.), Science Education: An International Course Companion (pp. 69-80). Rotterdam: The Netherlands: Sense Publishers. 
Citation:

Tang, K.S., \& Williams, P.J. (in press). STEM literacy or literacies? Examining the empirical basis of these constructs, Review of Education, doi: 10.1002/rev3.3162

Johri, A., Roth, W.-M., \& Olds, B. M. (2013). The Role of Representations in Engineering Practices: Taking a Turn towards Inscriptions. Journal of Engineering Education, 102(1), 2-19. doi:10.1002/jee.20005

Kaiser, G., \& Willander, T. (2005). Development of mathematical literacy: results of an empirical study. Teaching Mathematics and its Applications, 24, 48-60.

Kelly, G. J. (2008). Inquiry, activity, and epistemic practice. In R. Duschl \& R. Grandy (Eds.), Teaching scientific inquiry: Recommendations for research and implementation (pp. 99-117). Rotterdam: Sense Publishers.

Kelly, G. J. (2011). Scientific literacy, discourse, and epistemic practices. In C. Linder, L. Ostman, D. Roberts, P. Wickman, G. Erickson, \& A. MacKinnon (Eds.), Exploring the landscape of scientific literacy (pp. 61-73). London: Routledge.

Knain, E. (2006). Achieving science literacy through transformation of multimodal textual resources. Science Education, 90(4), 656-659.

Kress, G. (2003). Literacy in the new media age. London: Routledge.

Kramarski, B., \& Mizrachi, N. (2006). Online discussion and self-regulated learning: Effects of instructional methods on mathematical literacy. The Journal of Educational Research, 99(4), 218-223.

Lemke, J. L. (1990). Talking science: language, learning and values: Norwood, NJ: Ablex.

Lemke, J. L. (1998). Multiplying meaning: visual and verbal semiotics in scientific text. In J. Martin \& R. Veel (Eds.), Reading Science (pp. 87-113). London; New York: Routledge.

Lemke, J. L. (2000). Multimedia literacy demands of the scientific curriculum. Linguistics and Education, 10(3), 247-271.

Lemke, J. L. (2003). Mathematics in the middle: Measure, picture, gesture, sign, and word. In M. Anderson (Ed.), Educational perspectives on mathematics as semiosis: From thinking to interpreting to knowing (pp. 215-234). Ottawa: Legas.

Lemke, J. L. (2004). The literacies of science. In E. W. Saul (Ed.), Crossing borders in literacy and science instruction: Perspectives on theory and practice (pp. 33-47). Newark, DE: International Reading Association ; NSTA Press.

Liang, J., Jiang, Z. H., Zhao, Y. S., \& Wang, J. L. (2007). A meta-cognition modeling of engineering product designer in the process of product design. In Julie A. Jacko (Ed.), Human-Computer Interaction: Proceedings of the 12th International Interaction Design and Usability 2007 Conference (pp. 146-155). Berlin: Springer.

Lima, E. (1993). Culture revisited: Vygotsky's ideas in Brazil. Anthropology and Education Quarterly, 26(4), 443-457.

Mccormick, R., Murphy, P. \& Hennessy, S. (1994) Problem-Solving Processes in Technology Education: A Pilot Study. International Journal of Technology and Design Education 4, 5-34

Mercer, N., Dawes, L., Wegerif, R., \& Sams, C. (2004). Reasoning as a scientist: Ways of helping children to use language to learn science. British Educational Research Journal, 30(3), 359377.

Nathan, M. J., Srisurichan, R., Walkington, C., Wolfgram, M., Williams, C., \& Alibali, M. W. (2013). Building Cohesion Across Representations: A Mechanism for STEM Integration. Journal of Engineering Education, 102(1), 77-116. doi:10.1002/jee.20000

National Research Council. (2012). A Framework for K-12 Science Education: Practices, Crosscutting Concepts, and Core Ideas. Washington, DC: The National Academies Press.

Norris, S. P., \& Phillips, L. M. (2003). How literacy in its fundamental sense is central to scientific literacy. Science Education, 87(2), 224-240.

O'Halloran, K. L. (2005). Mathematical discourse: Language, symbolism and visual images. London, England: Continuum.

Pahl, G., Beitz, W., Feldhusen, J. \& Grote, K. (2007) Engineering Design. London: Springer.

Polya, G. (1973). How to solve it: A new aspect of mathematical method. Princeton, NJ: Princeton University Press.

Sfard, A. (2007). When the rules of discourse change, but nobody tells you: Making sense of mathematics learning from a commognitive standpoint. The journal of the learning sciences, 16(4), 567-615. 
Citation:

Tang, K.S., \& Williams, P.J. (in press). STEM literacy or literacies? Examining the empirical basis of these constructs, Review of Education, doi: 10.1002/rev3.3162

Shanahan, C., Shanahan, T., \& Misischia, C. (2011). Analysis of Expert Readers in Three Disciplines. Journal of Literacy Research, 43(4), 393-429. doi:doi:10.1177/1086296X11424071

Shanahan, T., \& Shanahan, C. (2008). Teaching disciplinary literacy to adolescents: Rethinking content-area literacy. Harvard Educational Review, 78(1), 40-59.

Shiverdecker, T., \& Fries-Gaither, J. (2015). STEM for all. Literacy and science: Better together. Educational Leadership, 72(4). [Online publication].

Tang, K. S. (2011) Hybridizing cultural understandings of the natural world to foster critical science literacy. (Doctoral dissertation, University of Michigan, 2011). Retrieved from Pro-Quest Dissertations and Theses.

Tang, K. S. (2013) Out-of-school media representations of science and technology and their relevance for engineering learning, Journal of Engineering Education, 101(1), 51-76. https://doi.org/10.1002/jee.20007.

Tang, K. S. (2015) The PRO instructional strategy in the construction of scientific explanations, Teaching Science, 61(4), 14-21.

Tang, K. S. \& Moje, E. (2010) Relating multimodal representations to the literacies of science, Research in Science Education, 40, 81-85. https://doi.org/10.1007/s11165-009-9158-5.

Tucker-Raymond, E., Gravel, B. E., Kohberger, K., \& Browne, K. (2017). Source code and a screwdriver: STEM literacy practices in fabricating activities among experienced adult makers. Journal of Adolescent \& Adult Literacy, 60(6). doi:10.1002/jaal.612

van der Wal, N. J., Bakker, A., \& Drijvers, P. (2017). Which Techno-mathematical Literacies Are Essential for Future Engineers? International Journal of Science and Mathematics Education, 15(1), 87-104. doi:10.1007/s10763-017-9810-x

Vygotsky, L. S. (1986). Thought and language (Translation newly rev. and edited / by Alex Kozulin ed.): Cambridge, Mass. : MIT Press, c1986.

Vygotsky, L. S., \& Cole, M. (1978). Mind in society the development of higher psychological processes. Cambridge, MA: Harvard University Press.

Wellington, J., \& Osborne, J. (2001). Language and literacy in science education. Philadelphia, PA: Open University Press.

Wells, J. (2016). Efficacy of the Technological/Engineering Design Approach: Imposed Cognitive Demands within Design-Based Biotechnology Instruction. Journal of Technology Education, 27(2), p. 4-20.

Wenger, E. (1998). Communities of practice: Learning, meaning, and identity, learning in doing. Cambridge, England; Cambridge University Press.

Williams, P.J. (1992) Technology Education in Australia: A Critical Analysis. Technology Education: A Global Perspective, ITEA/PATT International Conference (pp. 31-42). Washington, DC., USA

Williams, P J. (2000) Design: The only Methodology of Technology? Journal of Technology Education, 11(2), 48-61.

Williams, P. J. (2011) STEM Education: Proceed with caution, Design and Technology Education: an International Journal, 16(1).

Williams, P.J. (2014) Technological Literacy and Digital Democracy - a relationship grounded in Technology Education Chapter 4 in J. Dakers (Ed) New Frontiers in Technological Literacy. New York: Palgrave Macmillan, 59-76.

Yore, L. D., Bisanz, G. L., \& Hand, B. M. (2003). Examining the literacy component of science literacy: 25 years of language arts and science research. International Journal of Science Education, 25(6), 689 - 725.

Yore, L. (2011). Foundations of scientific, mathematical, and technological Literacies-Common themes and theoretical frameworks. In L. D. Yore, E. V. d. Flier-Keller, D. W. Blades, T. W. Pelton, \& D. B. Zandvliet (Eds.), Pacific CRYSTAL centre for science, mathematics, and technology literacy: Lessons learned (pp. 23-46). Rotterdam, The Netherlands: Sense.

Yore, L. D., \& Treagust, D. F. (2006). Current Realities and Future Possibilities: Language and science literacy - empowering research and informing instruction. International Journal of Science Education, 28(2), 291 - 314. 


\section{Citation:}

Tang, K.S., \& Williams, P.J. (in press). STEM literacy or literacies? Examining the empirical basis of these constructs, Review of Education, doi: 10.1002/rev3.3162

Zohar, A., \& Barzilai, S. (2015). Metacognition and teaching higher order thinking (HOT) in science education. In R. Wegerif, L. Li, \& J. C. Kaufman (Eds.), The Routledge International Handbook of Research on Teaching Thinking (pp. 229-242). New York: Routledge.

Zollman, A. (2012). Learning for STEM Literacy: STEM Literacy for Learning. School Science and Mathematics, 112(1), 12-19. doi:10.1111/j.1949-8594.2012.00101.x 